\title{
Peripheral nerve protein, Po, as a potential receptor for Theiler's murine encephalomyelitis virus
}

\author{
Jane E Libbey, ${ }^{1}$ Ingeborg J McCright, ${ }^{2}$ Ikuo Tsunoda, ${ }^{1}$ Yoshiaki Wada, ${ }^{3}$ and Robert S Fujinami ${ }^{1}$ \\ ${ }^{1}$ Department of Neurology, University of Utah School of Medicine, Salt Lake City, Utah, USA; ${ }^{2}$ Gene Expression \\ Database, Mouse Genome Informatics, The Jackson Laboratory, Bar Harbor, Maine, USA; and ${ }^{3}$ Department of Neurology, \\ Nissan Tamagawa Hospital, 4-8-1 Seta, Setagaya-ku, Tokyo, Japan
}

\begin{abstract}
Theiler's murine encephalomyelitis virus (TMEV) belongs the family Picornaviridae. TMEV not only replicates in the gastrointestinal tract but also spreads to the central nervous system (CNS) either by a hematogenous or a neural pathway during natural infection. The DA strain of TMEV infects neurons during the acute phase, and glial cells and macrophages during the chronic phase, leading to a demyelinating disease similar to multiple sclerosis. Different virus-host receptor interactions in the peripheral and the neuronal cells could explain the pathways of viral spread from the peripheral to the CNS and neurons to glial cells. However, the receptor for TMEV remains unknown. Po protein, a 28-31 kD glycoprotein, belongs to the immunoglobulin superfamily and constitutes $50 \%$ of the total myelin protein in the peripheral nerve. Other picornaviruses use members of the immunoglobulin superfamily as receptors. Thus we hypothesized P0 protein could act as a receptor for TMEV. In a virus overlay assay, radiolabeled TMEV bound to a $28-30 \mathrm{kD}$ protein from the peripheral nerve of wild-type $\mathrm{C57} \mathrm{BL} / 6$, but no binding was found in the peripheral nerve from P0-knockout mice. TMEV replicated fourfold higher in P0-transfected BW5147.G.1.4 cells than in mock-transfected cells. The increase in virus replication in the Po-transfected cell line was blocked by preincubation of the cells with anti-P0 antibody. A virus binding study showed that TMEV bound to P0-transfected cells but not to mock-transfected cells. The use of the P0 protein in Schwann cells as a receptor may be one mechanism by which TMEV spreads from the gastrointestinal tract to the CNS. Journal of NeuroVirology (2001) 7, 97-104.
\end{abstract}

Keywords: Cardiovirus infections; myelin P0 protein; peripheral nerves; Picornaviridae infections; virus receptors

\section{Introduction}

Theiler's murine encephalomyelitis viruses (TMEV) are naturally occurring enteric pathogens of mice (Theiler, 1937; Theiler and Gard, 1940). They are members of the family Picornaviridae and belong to the genus Cardiovirus. TMEV can be divided into two groups based on neurovirulence. The GDVII strain is highly neurovirulent while viruses in the TO group are less virulent and can cause a persistent central

Address correspondence to Robert S. Fujinami, PhD, Department of Neurology, University of Utah School of Medicine, 30N 1900E, 3R330, Salt Lake City, UT 84132, USA. E-mail: Robert. Fujinami@hsc.utah.edu

Received 10 March 2000; revised 30 August 2000; accepted 19 October 2000 nervous system (CNS) infection with inflammation and demyelination. DA virus (within the TO group) induces demyelinating disease and is one of the viral models that mimics many human demyelinating diseases, such as multiple sclerosis (MS) (reviewed in Tsunoda and Fujinami, 1999; Tsunoda et al, 1998).

Similar to poliovirus in humans, in nature, TMEV is spread from mouse to mouse by the oral-fecal route (Theiler, 1937; Theiler and Gard, 1940). In order to cause CNS infection and disease by this route, the virus must get from the alimentary tract and spread into the CNS. Several hypotheses have been proposed to explain dissemination into the CNS. They involve either hematogenous spread or intra-axonal transport (Martinat et al, 1999; Ren and Racaniello, 1992; Racaniello and Ren, 1994; Tyler et al, 1986) or 
a combination of both for the virus to get to the CNS. P0 protein is a $28-31 \mathrm{kD}$ glycoprotein, which constitutes approximately $50 \%$ of the total myelin proteins in the peripheral nervous system. Expression of P0 is limited to myelinating Schwann cells (Brown and Lemke, 1997; Uyemura et al, 1992). P0 is a single-pass integral membrane protein. The extracellular domain is hydrophobic and contains an immunoglobulin (Ig)-like motif, which defines P0 as a member of the Ig gene superfamily (Yoshihara et al, 1991). The extracellular domain is thought to function in myelin compaction at the intraperiod line through homophilic interactions. The intracellular domain is basic and has been suggested to function in the compaction of myelin at the major dense line (D’Urso et al, 1990; Filbin and Tennekoon, 1992). A second function attributed to P0 is in neurite outgrowth in regeneration and repair (reviewed in Spiryda, 1998).

It is known that various other picornaviruses use members of the Ig gene superfamily as receptors. These include poliovirus and rhinovirus. Poliovirus recognizes the poliovirus receptor (PVR/CD155), an integral membrane glycoprotein, which is a member of the Ig gene superfamily (Bernhardt et al, 1994; Mendelsohn et al, 1989; Racaniello, 1996). The receptor for the major human rhinovirus is intercellular adhesion molecule (ICAM)-1 (Greve et al, 1989; Lineberger et al, 1992; Harrison, 1993). ICAM-1 (CD54) is also a member of the Ig gene superfamily (Staunton et al, 1988). Huber (1994) identified another Ig superfamily molecule, vascular cell adhesion molecule 1 (VCAM-1, CD106) on vascular endothelial cells derived from the heart as a receptor for the D variant of encephalomyocarditis (EMC-D) virus that belongs to the genus Cardiovirus.

To date, only one possible receptor for TMEV has been reported but not identified or characterized (Kilpatrick and Lipton, 1991). Lipton and colleagues found that the BeAn (TO group) and GDVII viruses bound to a $34 \mathrm{kD}$ glycoprotein present in baby hamster kidney (BHK)-21 cells using a virus overlay assay. We have extended these studies using DA virus in an overlay assay to screen other cell lines and tissues from mice. Based on these initial screens, we proceeded to perform virus overlay assays on sciatic nerve isolated from P0 knockout (KO) and control mice. We also transfected BW5147.G.1.4 (BW) cells with $\mathrm{P} 0$ to determine if the expressed $\mathrm{P} 0$ protein could function as a receptor for the DA virus. Using the above approach, we have identified P0 protein as a potential receptor for TMEV.

\section{Results}

Virus overlay assay

Virus overlay assays were performed using TMEV permissive BHK-21 and nonpermissive BSC-1 cell lines and tissues from SJL/J mice-a strain known to be susceptible to TMEV infection. As can be seen in

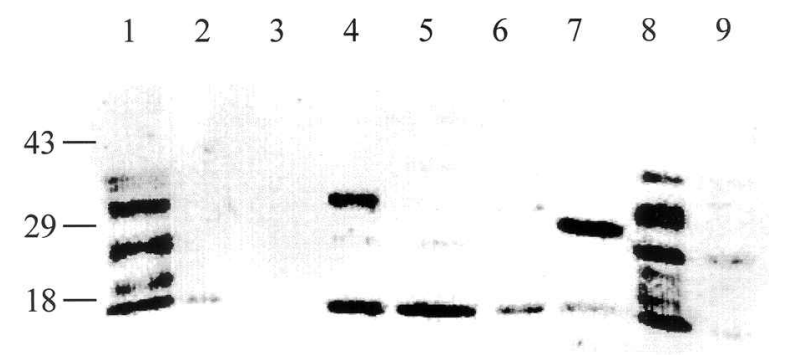

Figure 1 Virus overlay assay of two cell lines and tissues from SJL/J mice. Lanes are as follows: 1, BHK-21; 2, BSC-1; 3, hippocampus; 4 , spinal cord; 5 , cerebellum; 6 , brain stem; 7 , peripheral nerve; 8 , total brain; 9, kidney. BHK-21 and BSC-1 are known to be permissive and nonpermissive to TMEV infection, respectively. Radiolabeled DA virus was detected on the membrane to which proteins from cell lines and tissues were transferred. Note a prominent $28-30 \mathrm{kD}$ band in peripheral nerve (lane 7).

Figure 1 (lane 1), DA virus binds to several proteins separated from BHK-21 cells including prominent bands at approximately $33-34 \mathrm{kD}$ and $18 \mathrm{kD}$. Kilpatrick and Lipton (1991) reported BeAn and GDVII viruses binding to these proteins as well. We also observed this with DA virus and found that DA virus was also able to bind to a $20 \mathrm{kD}$ and $26 \mathrm{kD}$ band. In BSC-1 cells (lane 2), there was some binding to a faint band at about $16 \mathrm{kD}$. The hippocampus (lane 3) shows little or no attachment of virus to any band. However, this may reflect our inability to obtain enough pure hippocampal material or the potential receptors are in low abundance or denatured since DA virus can efficiently infect hippocampal neurons in vivo (Wada and Fujinami, 1993). In spinal cord (lane 4), two prominent bands were observed to bind virus. One band has a similar migration pattern to the $33-34 \mathrm{kD}$ protein of $\mathrm{BHK}-21$ cells and the other at $16 \mathrm{kD}$. In cerebellum (lane 5) and in the brain stem (lane 6) a $16 \mathrm{kD}$ band was also seen. The $16 \mathrm{kD}$ band may not be a true receptor, since BSC-1 cells also have a band in this area and DA virus is not usually found in the cerebellum. Alternatively, the BSC-1 band and that observed in other tissue types are different proteins, which happen to migrate in the same area of the gel. Total brain extract (lane 8) had a similar binding pattern as

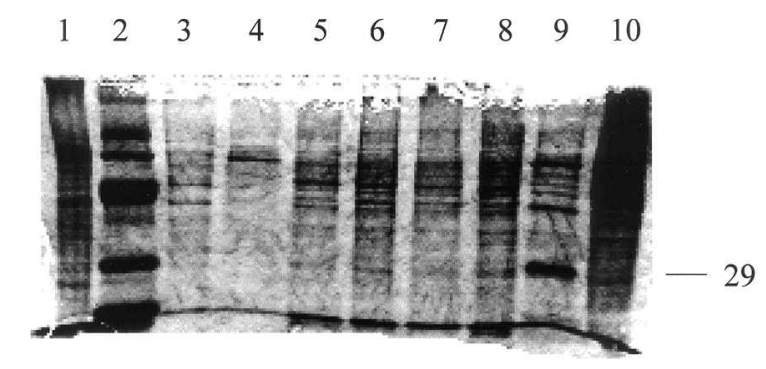

Figure 2 Coomassie stained SDS-PAGE gel of two cell lines and tissues from SJL/J mice. Lanes are as follows: 1, kidney; 2, marker; 3, BHK-21; 4, BSC-1; 5, hippocampus; 6 , spinal cord; 7, cerebellum; 8 , brain stem; 9 , peripheral nerve; 10 , total brain. Note a prominent 28-30 kD band in peripheral nerve (lane 9). 


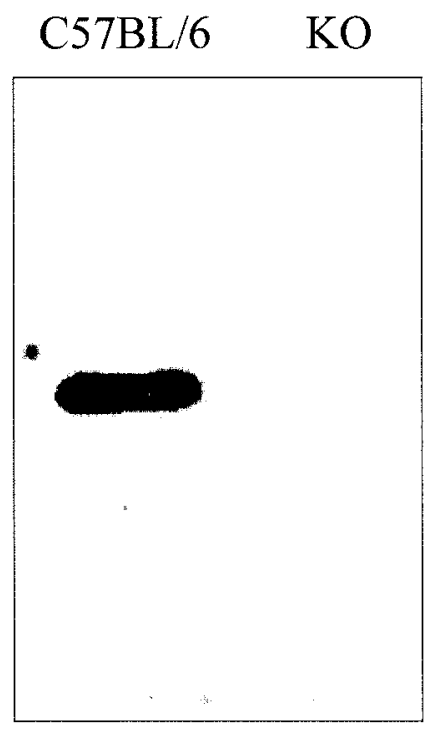

Figure 3 Virus overlay assay of sciatic nerve. C57BL/6 control nerve is on the left and the P0 knockout (KO) mouse sciatic nerve is on the right. Radiolabeled DA virus binding to a $28-30 \mathrm{kD}$ protein was detected in wild type C57BL/6 mice (left), but not in P0 KO mice on a C57BL/6 background (right).

BHK-21 cells and in kidney (lane 9) virus binds to a $26 \mathrm{kD}$ band and a $16 \mathrm{kD}$ band.

Interestingly, DA virus attached to a prominent 28$30 \mathrm{kD}$ band in peripheral nerve (lane 7). In pursuing what protein the virus bound to in peripheral nerve (sciatic nerve), we were struck by the amount of this protein in Coomassie blue stained gels (Figure 2, lane 9). A very prominent protein in peripheral nerve is the P0 protein of myelin and it is the appropriate molecular weight $(28-30 \mathrm{kD})$. To determine whether the virus could bind to P0 protein, P0 knockout (KO) mice were obtained from Dr. Phil Soriano at the Fred Hutchenson Cancer Research Center. Two homozygous P0 KO mice on a C57BL/6 background were obtained (Giese et al, 1992). Sciatic nerve was processed from these $\mathrm{KO}$ mice and control C57BL/6 mice. A virus overlay assay was performed using the homozygous KO sciatic nerve versus the control C57BL/6 sciatic nerve. The very prominent band on the left was approximately 28-30 kD (Figure 3) and demonstrated radiolabeled DA virus binding to P0 protein in control mouse sciatic nerve. DA virus did not bind to a similar migrating band from the PO KO mice (right lane). This suggests that the virus has the ability to bind to P0.

\section{Sequence comparison}

A sequence comparison was performed between the $\mathrm{DA}$ virus coding region and P0. There is a 20 amino

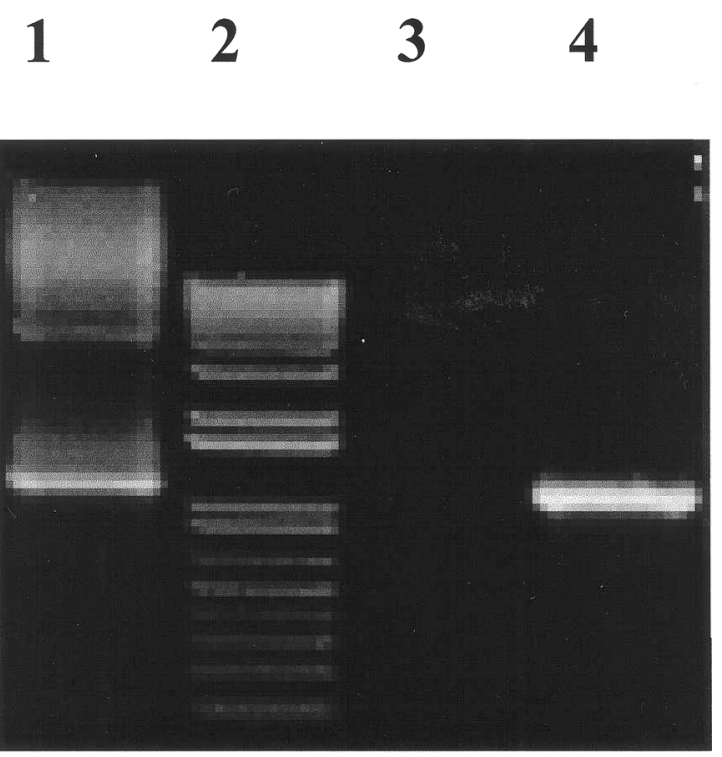

Figure 4 Ethidium bromide stained agarose gel of PCR products from 1, P0/pRc-CMV\#4, P0 cDNA expressing vector; 2, marker; 3 , mock transfected BW cells; 4, P0 transfected BW cells (P0/BW). P0 plasmid was detected in P0/BW cells (lane 4) but not in mock transfected BW cells (lane 3).

acid stretch in the extracellular domain of P0 and the loop I and loop II of VP-1 in DA virus (Table 1). Six amino acids are shared over this region of 20 and by the sequence similarity program (SCANSIM), this region shares over $60-70 \%$ overall similarity.

\section{Expression of P0 protein in BW5147.G.1.4 cells}

BW cells were selected for this study based on their inability to be infected by DA virus at low multiplicity of infection (MOI) and their ability to support viral replication upon infection at much higher MOI or upon transfection with viral RNA (Fotiadis et al, 1991; Kilpatrick and Lipton, 1991; McCright and Fujinami, 1997). The TMEV strain GDVII was not used in this study due to its ability to infect BW cells at low as well as high MOIs. This is in contrast to the finding by Fotiadis et al (1991) that GDVII does not productively infect BW. We assayed for the presence of the constitutive, mammalian expression vector constructed to express the P0 cDNA product, P0/pRc-CMV\#4, after transfection into BW cells and selection via PCR on plasmid samples prepared from the transfected cells. Figure 4 shows the presence of the plasmid in the transfected cells but not in mock transfected cells (lane 3 versus lane 4).

The P0 transfect BW (P0/BW) cells were then infected with DA virus at various MOI's, and virus was quantified. The results are presented in Table 2.

Table 1 Sequence similarity between loop I and loop II of VP-1 and P0 protein

\begin{tabular}{|c|c|c|c|c|c|c|c|c|c|c|c|c|c|c|c|c|c|c|c|c|}
\hline DA virus loop I and loop II of VP-1 & $\begin{array}{c}82 \\
\text { S } \\
55\end{array}$ & G & $\mathrm{P}$ & $\mathbf{V}$ & $\mathrm{K}$ & $\mathrm{T}$ & $\mathrm{K}$ & A & $\mathrm{P}$ & $\mathrm{V}$ & Q & $\mathbf{W}$ & $\mathbf{R}$ & W & $\mathrm{V}$ & $\mathrm{R}$ & $\mathrm{S}$ & G & G & $\begin{array}{c}101 \\
\mathrm{~T} \\
74\end{array}$ \\
\hline P0 protein & $\mathbf{S}$ & $\mathrm{E}$ & W & $\mathbf{V}$ & $\mathrm{S}$ & $\mathrm{D}$ & $\mathrm{D}$ & I & $\mathrm{S}$ & $\mathrm{F}$ & $\mathrm{T}$ & $\mathbf{W}$ & $\mathbf{R}$ & $\mathrm{Y}$ & Q & $\mathrm{P}$ & $\mathrm{E}$ & G & G & $\mathrm{R}$ \\
\hline
\end{tabular}


Table 2 Infectivity of BW cells transfected with P0

\begin{tabular}{rrr}
\hline & \multicolumn{2}{c}{$P F U / m l$} \\
\cline { 2 - 3 } MOI & $B W$ & $P 0 / B W \# 6$ \\
\hline 0.1 & 0 & $14^{* *}$ \\
1.0 & 35 & $156^{* *}$ \\
10.0 & 173 & $675^{* *}$ \\
\hline
\end{tabular}

${ }^{* *} P<0.01$, compared with BW. Student's $t$-test.

It can clearly be seen that there is a fourfold increase in the amount of virus in the P0 expressing P0/BW cells over the BW control cells. This experiment was performed in duplicate four times with similar results. Using the Student's $t$-test, this difference was found to be statistically significant $(P<0.01)$.

Using polyclonal anti-P0 antibody, we tested whether preincubation of $\mathrm{P} 0 / \mathrm{BW}$ cells with anti-P0 antibody could block DA virus infection in P0/BW cells. The incubation of the cells with antibody against P0 decreased the ability of the virus to infect P0/BW cells by more than $80 \%$, but had no effect on control BW cells, when compared to preincubation with PBS (Figure 5). Using the Student's $t$-test, this difference was found to be statistically significant $(P<0.01)$. The normal rabbit serum had no effect on

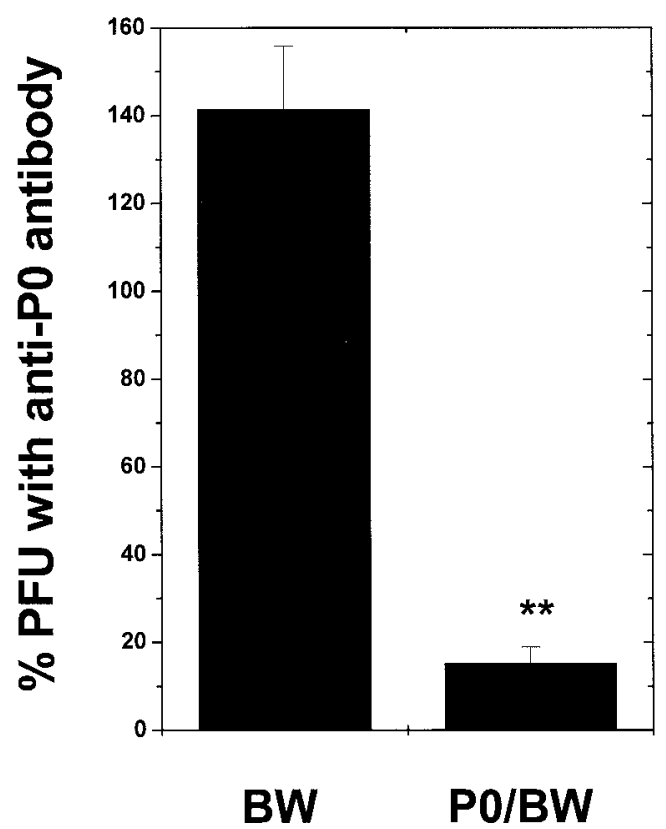

Figure 5 Blocking of infections with anti-P0 antibody. Control BW (left) and P0 transfected BW (P0/BW, right) cells were incubated for 1 hour either with anti-P0 antibody or PBS. The cells were infected with DA virus at a MOI of 1 and 10. After overnight incubation, the cells and supernatant were harvested. Plaque assays were performed. PFU was compared between anti-P0 antibody and PBS incubation groups as follows: \% PFU with anti-P0 antibody $=(\mathrm{PFU}$ with anti-P0 antibody $) /(\mathrm{PFU}$ with $\mathrm{PBS}) \times 100$. Anti-P0 antibody blocked DA virus replication more than $80 \%$ in $\mathrm{P} 0 / \mathrm{BW}$ cells $(* * ; P<0.01$, Student's $t$-test), while no inhibition was seen in control BW cells. Values are mean \pm SEM.

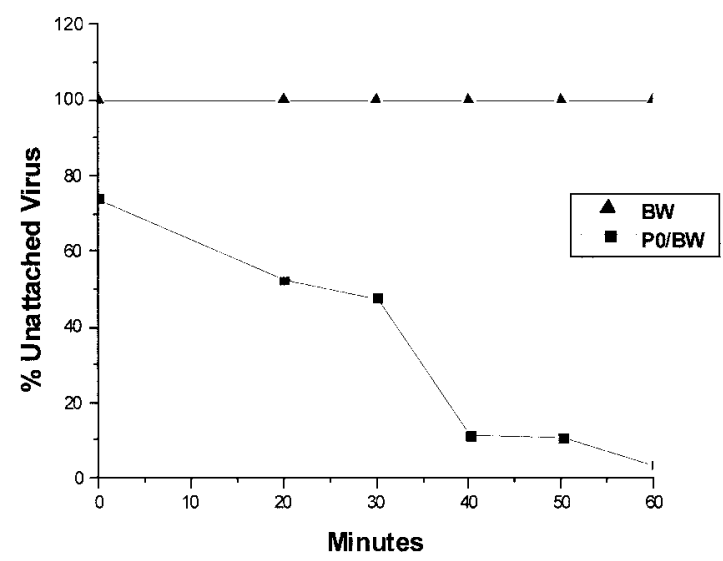

Figure 6 Kinetics of binding of DA virus to control BW and P0 transfected BW (P0/BW) cells. Cells were incubated with DA virus at an MOI of 5 on ice and unattached virus was titrated in the supernatent every 10 min postincubation. No virus binding was detected in BW cells, while most viruses attached to P0/BW.

the ability of the virus to infect either BW or P0/BW cells (data not shown).

We compared DA virus binding between control BW cells and P0/BW cells to see whether an increase in virus replication in vitro in $\mathrm{P} 0 / \mathrm{BW}$ cells was due to altered virus binding on P0/BW cells. The result of the attachment study is presented in Figure 6. The ability of BW cells expressing P0 to bind to DA virus can clearly be seen. Attachment was $90 \%$ complete after $40 \mathrm{~min}$, demonstrating virus binding to P0/BW cells.

\section{Discussion}

TMEV most likely uses several receptors to enter various cell types, i.e., peripheral neurons or Schwann cells (P0) (Uyemura et al, 1992; Brown and Lemke, 1997) versus glial versus other cell types such as BHK-21 cells (34 kD glycoprotein). Limited receptor expression is one way to explain species specificity and restricted tissue tropism of viruses (Holmes et al, 1997). Since both GDVII and TO subgroups could be isolated from feces up to 53 days (Theiler and Gard, 1940) and 154 days (Brownstein et al, 1989), respectively, postinfection, invasion into the CNS via the neural route from a persistent infection in the intestine may be one pathway, as originally suggested by Theiler and Gard (1940). Thus, although there have been no published reports of peripheral nerve involvement in TMEV infection by the i.c. route (Dal Canto, 1982), the peripheral nerves may be one way the virus travels from the alimentary tract to the CNS during a natural infection. Rustigian and Pappenheimer (1949) suggested that TMEV could reach the CNS via peripheral nerve. In this earlier study, after intramuscular injection, GDVII virus caused flaccid paralysis first in the injected limb and later in the opposite limb. Moreover, Frankel et al 
(1986) have reported that Schwann cells are susceptible to DA virus infection in vitro.

Many of the picornavirus receptors, such as PVR and ICAM-1 for poliovirus and major human rhinovirus respectively, belong to the Ig gene superfamily (Greve et al, 1989; Mendelsohn et al, 1989; Harrison, 1993; Lineberger et al, 1992; Bernhardt et al, 1994; Racaniello, 1996). Membership in this family is defined by the presence of one or several common structural units, the Ig domain (Yoshihara et al, 1991). Members of this family are important adhesion and ligand molecules (Albelda and Buck, 1990; Yong and Khwaja, 1990; Yoshihara et al, 1991). These molecules are thought to be involved in cellcell adhesion in embryogenesis, wound healing, and the inflammatory response (Albelda and Buck, 1990). Ig superfamily members can act as a receptor-ligand pair where both are members of the Ig family or they can act alone through homophilic binding with self (Albelda and Buck, 1990). P0 is also a member of this family as defined by the presence of one Ig domain (Lemke et al, 1988). It is thought that P0 is involved in homotypic interactions for myelin compaction to occur (Filbin et al, 1990; D'Urso et al, 1990; Lemke, 1993). Thus, this observation of P0 being a potential receptor is consistent with data from other picornaviruses.

TMEV have four capsid proteins, VP-1, VP-2, VP-3, and VP-4 (Lipton and Friedmann, 1980; Stroop and Baringer, 1981). VP-1 is an external capsid protein with two highly exposed loop regions as determined by X-ray crystallography of the DA virus (Grant et al, 1992). Loop II of VP-1 is important in the pathogenesis of the virus (Zurbriggen et al, 1991; Wada et al, 1994; Wada et al, 1998). Loop I of VP-1 has also been shown via site-directed mutagenesis experiments to be important in the pathogenesis of the virus (McCright, 1997; McCright et al, 2001). Loop I forms a protrusion from the surface of the virion and would be compatible with the loop being a finger interacting with a cleft on a receptor molecule. The 20 amino acid region of sequence similarity between loop I and loop II of VP-1 and P0 is a potential site for inhibition studies with polyclonal anti-P0 antibody and/or further mutagenesis analyses on the viral genome as well as the P0 domain. Because P0 forms homotypic interactions with itself, a testable possibility is the extracellular domain of $\mathrm{P} 0$ and loop I and II of VP-1 interact with each other at this region. P0 interacts with self and thus obviously has at least one region of sequence homology with self through which this interaction occurs. One could envision the interaction occurring by means of just one region of homology or by means of several regions in which region A of protein 1 interacts with region $B$ of protein 2 and vice versa. For P0 to interact with non-self, one would expect the non-self protein to also carry the region(s) of homology necessary for interaction to occur.
Zhou et al (2000) recently found that DA strain of TMEV binding is dependent on the interaction of the virus with both the protein surface and a sialic acid moiety of the host glycoprotein receptor. P0 has been shown to be a glycoprotein which has sialic acid (Filbin and Tennekoon, 1992). The glycosylation has been mapped to Asp122 of the P0 protein which is extracellular and is thought to play a role in $\mathrm{P} 0 / \mathrm{P0}$ interactions (Filbin and Tennekoon, 1992; Uyemura et al, 1992). The site on TMEV which binds the sialic acid was found to be located at the interface between VP-1 and VP-2, at the rim of the "pit" postulated to be the receptor binding site (Zhou et al, 2000). Thus, if $\mathrm{DA}$ virus is able to interact with the sialic acid of P0 and the protein surface of P0, possibly at the point of sequence homology, then DA virus could use P0 as a receptor to enter Schwann cells. The removal of sialic acid from P0 via the use of sialidase or occupying the sialic acid binding site of the virus with sialyllactose would test this hypothesis (Zhou et al, 2000).

BW cells are not infected by DA virus at low MOI but can be infected at much higher MOI (Fotiadis et al, 1991; Kilpatrick and Lipton, 1991; McCright and Fujinami, 1997). This infectivity may be due to the presence of an inefficient and/or low abundance receptor on the BW cells. P0 could function as a coreceptor that is able to enhance the binding ability of the inefficient/low abundant BW receptor resulting in higher infectivity at lower MOI.

In this paper, we demonstrated that DA virus bound to myelin P0 protein in a virus overlay assay and that DA virus replicated fourfold more efficiently in P0 transfected BW cells than in control BW cells. This increase in virus replication was blocked by anti-P0 antibody. P0-transfected BW cells, but not control BW cells, bound DA virus in a virus binding assay. This is the first evidence that DA virus can use P0 protein as a receptor in vitro. Although we do not know whether P0 protein can serve as a virus receptor in vivo, the use of the P0 protein in Schwann cells as a receptor may be one mechanism by which TMEV spreads from the gastrointestinal tract to the CNS.

\section{Materials and Methods}

\section{Cells, virus, and medium}

BW5147.G.1.4 (American Type Culture Collection (ATCC), Rockville, MD) and BHK-21 (ATCC) cells were maintained in Dulbecco's modified Eagle's medium (DMEM) (Mediatech, Herndon, VA) supplemented with $10 \%$ fetal bovine serum (FBS) (Life Technologies, Grand Island, NY), 1\% glutamine (Mediatech) and 1\% antibiotics (Mediatech). BSC-1 cells (African green monkey kidney cell line) (ATCC) were maintained in complete minimal essential medium (MEM) (Life Technologies). The DA strain of TMEV and its propagation have been described previously (Zurbriggen and Fujinami, 1989). 
Virus overlay assay

DA virus was radiolabeled as follows: BHK-21 cells at $80 \%$ confluency in T150 flasks (Greiner, Kremsmünster, Austria) were infected with DA virus at $7 \times 10^{7}$ plaque forming unit (PFU)/flask. The virus was allowed to absorb for $1 \mathrm{~h}$ at $37^{\circ} \mathrm{C}$, and the cells were then washed with serum-free DMEM. Cells were incubated for $30 \mathrm{~min}$ at $37^{\circ} \mathrm{C}$ and then washed two times with DMEM lacking serum and phosphate. The cells were incubated for $1 \mathrm{~h}$ at $37^{\circ} \mathrm{C}$ and then medium was added containing $83 \mu \mathrm{Ci}$ of ${ }^{32} \mathrm{P}$ per $\mathrm{ml}$ ( $1 \mathrm{mCi} /$ flask) in the form of ${ }^{32} \mathrm{P}$-orthophosphate (Amersham, Arlington Heights, IL). The cells were incubated overnight at $37^{\circ} \mathrm{C}$. Virus was purified as described previously (McCright, 1997; McCright et al, 2001). Purified virus was resuspended in $1 \mathrm{ml}$ PBS such that $1 \mu \mathrm{l}$ was about $3000 \mathrm{cpm}$.

Proteins were prepared in various ways depending on the source. Tissues were harvested from mice (Jackson Laboratory, Bar Harbor, ME) at 12 weeks of age and minced with scissors. Next, phenylmethylsulfonyl fluoride (PMSF) (1 mM) (Sigma, St. Louis, MO), aprotinin (10 $\mu \mathrm{g} / \mathrm{ml})$ (bovine lung) (Sigma) and EDTA (5 mM) (JT Baker, Phillipsburg, NJ) were added to the sample and the tissue homogenized resulting in final concentrations as listed. The homogenate was centrifuged at $100 \times \mathrm{g}$ for $5 \mathrm{~min}$ and the supernatent was collected and centrifuged at $27000 \times \mathrm{g}$ for $15 \mathrm{~s}$. The supernatent was collected, and the amount of protein was determined using the Bio-Rad Protein Assay (Bio-Rad, Hercules, CA). The only difference for the preparation of the P0 knockout mice was that the centrifugations were at $600 \times \mathrm{g}$ for $15 \mathrm{~min}$ and $27000 \times \mathrm{g}$ for $1 \mathrm{~min}$.

Proteins were prepared from cell lines as follows: the cells were washed with Hanks balanced salt solution (Mediatech), incubated with $50 \mathrm{mM}$ EDTA in Hanks solution for $10 \mathrm{~min}$ at room temperature, and centrifuged at $70 \times \mathrm{g}$ for $5 \mathrm{~min}$ at $4^{\circ} \mathrm{C}$. The pellet was washed once with PBS and incubated for $5 \mathrm{~min}$ at $4^{\circ} \mathrm{C}$. Then, $1 \mathrm{mM}$ PMSF, $10 \mu \mathrm{g} / \mathrm{ml}$ aprotinin, and $5 \mathrm{mM}$ EDTA were added, the cells were homogenized and centrifuged at $300 \times \mathrm{g}$ for $5 \mathrm{~min}$. The supernatent was again centrifuged at $27000 \times \mathrm{g}$ for $20 \mathrm{~s}$.

SDS-PAGE gels and protein transfers to membrane were performed as previously described (Fujinami and Oldstone, 1980; Fujinami et al, 1983). Prior to the virus overlay, membranes were blocked with $3 \%$ bovine serum albumin (BSA) (Sigma) for $1 \mathrm{~h}$ at room temperature. The membranes were then incubated with ${ }^{32} \mathrm{P}$-DA virus for $1 \mathrm{~h}$ at room temperature. The membranes were then washed three times for $15 \mathrm{~min}$, dried, and put on film.

\section{Cloning}

The plasmid pSN63, which contains the cDNA for rat P0, was obtained from Dr. Greg Lemke (Salk Institute for Biological Studies, La Jolla, CA). The transformation, preparation, and subsequent cloning of the
P0 gene was done using standard molecular biology techniques (Sambrook et al, 1989). The P0 gene region was isolated from the pSN63 vector using the restriction enzymes Xba I (Life Technologies) and EcoR I (Life Technologies) and subsequently blunt ligated into the pRc-CMV vector (Invitrogen, San Diego, CA) digested with BstX I (Life Technologies) and blunted. The resultant clone, P0/pRc-CMV\#4, was selected based on restriction enzyme digestion mapping and DNA sequencing.

\section{Transfection/infection}

The P0/pRc-CMV\#4 plasmid DNA was transfected into BW cells using DMRIE-C (Life Technologies) according to the manufacturer's instructions. The transfectants were selected with $1 \mathrm{mg} / \mathrm{ml} \mathrm{G} 418$ (Calbiochem, La Jolla, CA) for 1 week and then the amount of drug was decreased to $0.5 \mathrm{mg} / \mathrm{ml}$.

The presence of the plasmid in the BW cells was confirmed via PCR on plasmid DNA prepared by means of the QIAprep spin miniprep kit (Qiagen, Chatsworth, CA) as follows: $1.5 \mathrm{ml}$ of cell culture was centrifuged, the pellet was resuspended in $850 \mu \mathrm{l}$ of the P1 buffer supplied with the kit and the tubes were freeze/thawed three times in a dry ice ethanol bath $/ 37^{\circ} \mathrm{C}$ water bath. The cell lysate was centrifuged and the supernatent was applied to the column, washed, and eluted according to the manufacturer's instructions. PCR was performed using the T7 and Sp6 primers, which prime within the vector sequences outside of the P0 gene insert.

P0 transfected BW cells and BW control cells at $2 \times 10^{6}$ cells/well in six-well plates were infected with DA virus at MOIs of $0,0.1,1$, and 10 for $1 \mathrm{~h}$ at $37^{\circ} \mathrm{C}$. The cultures were washed three times with PBS and $3 \mathrm{ml}$ medium was added. The cultures were incubated overnight at $37^{\circ} \mathrm{C}$ in $5 \% \mathrm{CO}_{2}$ and then the cells and supernatent were harvested, freeze/thawed two times and stored at $-70^{\circ} \mathrm{C}$. Plaque assays were performed as described previously (Zurbriggen and Fujinami, 1989). The antibody blockage experiment was done as above with the addition, prior to the infection, of a 1-h incubation of the cells at $37^{\circ} \mathrm{C}$ in $5 \% \mathrm{CO}_{2}$ in the presence of either $1 \mathrm{ml}$ PBS, normal rabbit serum, or polyclonal rabbit antibody against P0.

\section{Attachment/binding}

BW and P0/BW cells were incubated with DA virus at an MOI of 5 on ice for $1 \mathrm{~h}$. Samples of $1 \mathrm{ml}$ volume were taken at time 0 and every $10 \mathrm{~min}$ from time $20 \mathrm{~min}$ to time $60 \mathrm{~min}$. A control tube with no cells tested for attachment of the virus to the tube and inactivation of the virus over time. The 1-ml samples were centrifuged for $5 \mathrm{~min}$ at $1000 \times \mathrm{g}$ at $4^{\circ} \mathrm{C}$ and the supernatent was removed to a new tube and frozen at $-70^{\circ} \mathrm{C}$. Plaque assays were performed as described previously (Zurbriggen and Fujinami, 1989). 


\section{Acknowledgements}

We wish to thank Dr. Phil Soriano at the Fred Hutchenson Cancer Research Center for his generous donation of the P0 knockout mice. We also wish to thank Dr. G. Lemke at the Salk Institute for Biological Studies for the rat P0 cDNA clone. We also

\section{References}

Albelda SM, Buck CA (1990). Integrins and other cell adhesion molecules. FASEB J 4: 2868-2880.

Bernhardt G, Bibb JA, Bradley J, Wimmer E (1994). Molecular characterization of the cellular receptor for poliovirus. Virology 199: 105-113.

Brown AM, Lemke G (1997). Multiple regulatory elements control transcription of the peripheral myelin protein zero gene. J Biol Chem 272: 28939-28947.

Brownstein D, Bhatt P, Ardito R, Paturzo F, Johnson E (1989). Duration and patterns of transmission of Theiler's mouse encephalomyelitis virus infection. $L a b$ Anim Sci 39: 299-301.

Dal Canto MC (1982). Uncoupled relationship between demyelination and primary infection of myelinating cells in Theiler's virus encephalomyelitis. Infect Immun 35: 1133-1138.

D’Urso D, Brophy PJ, Staugaitis SM, Gillespie CS, Frey AB, Stempak JG, Colman DR (1990). Protein zero of peripheral nerve myelin: biosynthesis, membrane insertion, and evidence for homotypic interaction. Neuron 2: 449-460.

Filbin MT, Tennekoon GI (1992). Myelin P0-protein, more than just a structural protein? Bioessays 14: 541-547.

Filbin MT, Walsh FS, Trapp BD, Pizzey JA, Tennekoon GI (1990). Role of myelin P0 protein as a homophilic adhesion molecule. Nature 344: 871-872.

Fotiadis C, Kilpatrick DR, Lipton HL (1991). Comparison of the binding characteristics to BHK-21 cells of viruses representing the two Theiler's virus neurovirulence groups. Virology 182: 365-370.

Frankel G, Friedmann A, Amir A, David Y, Shahar A (1986). Theiler's virus replication in isolated Schwann cell cultures. J Neurosci Res 15: 127-136.

Fujinami RS, Oldstone MBA (1980). Alterations in expression of measles virus polypeptides by antibody: molecular events in antibody-induced antigenic modulation. J Immunol 125: 78-85.

Fujinami RS, Oldstone MBA, Wroblewska Z, Frankel ME, Koprowski H (1983). Molecular mimicry in virus infection: crossreaction of measles virus phosphoprotein or of herpes simplex virus protein with human intermediate filaments. Proc Natl Acad Sci USA 80: 23462350.

Giese KP, Martini R, Lemke G, Soriano P, Schachner M (1992). Mouse Po gene disruption leads to hypomyelination, abnormal expression of recognition molecules, and degeneration of myelin and axons. Cell 71: 565-576.

Grant RA, Filman DJ, Fujinami RS, Icenogle JP, Hogle JM (1992). Three-dimensional structure of Theiler virus. Proc Natl Acad Sci USA 89: 2061-2065.

Greve JM, Davis G, Meyer AM, Forte CP, Yost SC, Marlor CW, Kamarck ME, McClelland A (1989). The major human rhinovirus receptor is ICAM-1. Cell 56: 839-847. wish to thank Dr. Marie Filbin at Hunter College for polyclonal antibody against $\mathrm{P0}$ protein. Thanks also to Kristie Parker, Jana Blackett, Loren Jack, David Liechty, and Thomas Cannon for their excellent technical assistance and Kathleen Borick for the preparation of the manuscript. Work supported by NIH NS34497.

Harrison SC (1993). Common cold virus and its receptor. Proc Natl Acad Sci USA 90: 783.

Holmes KV, Tresnan DB, Zelus BD (1997). Virus-receptor interactions in the enteric tract. Virus-receptor interactions. Adv Exp Med Biol 412: 125-133.

Huber SA (1994). VCAM-1 is a receptor for encephalomyocarditis virus on murine vascular endothelial cells. $J$ Virol 68: 3453-3458.

Kilpatrick DR, Lipton HL (1991). Predominant binding of Theiler's viruses to a 34-kilodalton receptor protein on susceptible cell lines. J Virol 65: 5244-5249.

Lemke G (1993). The molecular genetics of myelination: an update. Glia 7: 263-271.

Lemke G, Lamar E, Patterson J (1988). Isolation and analysis of the gene encoding peripheral myelin protein zero. Neuron 1: 73-83.

Lineberger DW, Uncapher CR, Graham DJ, Colonno RJ (1992). Domains 1 and 2 of ICAM- 1 are sufficient to bind human rhinoviruses. Virus Res 24: 173-186.

Lipton HL, Friedmann A (1980). Purification of Theiler's murine encephalomyelitis virus and analysis of the structural virion polypeptides: correlation of the polypeptide profile with virulence. J Virol 33: 11651172.

Martinat C, Jarousse N, Prévost M-C, Brahic M (1999). The GDVII strain of Theiler's virus spreads via axonal transport. J Virol 73: 6093-6098.

McCright, IJ (1997). Theiler's viruses with mutations in capsid protein VP1 lead to altered virus entry and pathogenesis. Doctoral Dissertation, University of Utah, Salt Lake City, Utah.

McCright IJ, Fujinami RS (1997). Lack of correlation of Theiler's virus binding to cells with infection. J Neurovirol 3 Suppl 1: S68-S70.

McCright IJ, Tsunoda I, Libbey JE, Fujinami RS (2001). Mutation in loop I of VP1 of Theiler's virus leads to a reduced penetration rate without altering binding or uncoating. In preparation.

Mendelsohn CL, Wimmer E, Racaniello VR (1989). Cellular receptor for poliovirus: molecular cloning, nucleotide sequence, and expression of a new member of the immunoglobulin superfamily. Cell 56: 855-865.

Racaniello VR (1996). Early events in poliovirus infection: virus-receptor interactions. Proc Natl Acad Sci USA 93: 11378-11381.

Racaniello VR, Ren R (1994). Transgenic mice and the pathogenesis of poliomyelitis. Arch Virol Suppl 9: 7986.

Ren R, Racaniello VR (1992). Poliovirus spreads from muscle to the central nervous system by neural pathways. $J$ Infect Dis 166: 747-752.

Rustigian R, Pappenheimer AM (1949). Myositis in mice following intramuscular injection of viruses of the 
mouse encephalomyelitis group and of certain other neurotropic viruses. J Exp Med 89: 69-92.

Sambrook J, Fritsch EF, Maniatis T (1989). Molecular cloning: A laboratory manual. 2nd ed. New York: Cold Spring Harbor Laboratory Press.

Spiryda LB (1998). Myelin protein zero and membrane adhesion. J Neurosci Res 54: 137-146.

Staunton DE, Marlin SD, Stratowa C, Dustin ML, Springer TA (1988). Primary structure of ICAM-1 demonstrates interaction between members of the immunoglobulin and integrin supergene families. Cell 52: 925-933.

Stroop WG, Baringer JR (1981). Biochemistry of Theiler's murine encephalomyelitis virus isolated from acutely infected mouse brain: identification of a previously unreported polypeptide. Infect Immun 32: 769-777.

Theiler M (1937). Spontaneous encephalomyelitis of mice, a new virus disease. J Exp Med 65: 705-719.

Theiler M, Gard S (1940). Encephalomyelitis of mice. III. Epidemiology. J Exp Med 72: 79-90.

Tsunoda I, Fujinami RS (1999). Theiler's murine encephalomyelitis virus. In: Persistent viral infections. Ahmed R, Chen I (eds). Chichester: Wiley, pp 517-536.

Tsunoda I, Kuang L-Q, Tolley ND, Whitton JL, Fujinami RS (1998). Enhancement of experimental allergic encephalomyelitis (EAE) by DNA immunization with myelin proteolipid protein (PLP) plasmid DNA. J Neuropathol Exp Neurol 57: 758-767.

Tyler KL, McPhee DA, Fields BN (1986). Distinct pathways of viral spread in the host determined by reovirus S1 gene segment. Science 233: 770-774.

Uyemura K, Kitamura K, Miura M (1992). Structure and molecular biology of P0 protein. In: Myelin: Biology and chemistry. Martenson RE, (ed). Boca Raton, FL: CRC Press, pp 481-508.

Wada Y, Fujinami RS (1993). Viral infection and dissemination through the olfactory pathway and the limbic system by Theiler's virus. Am J Pathol 143: 221229.

Wada Y, McCright IJ, Whitby FG, Tsunoda I, Fujinami RS (1998). Replacement of loop II of VP-1 of the DA strain with loop II of the GDVII strain of Theiler's murine encephalomyelitis virus alters neurovirulence, viral persistence and demyelination. J Virol 72: 7557-7562.

Wada Y, Pierce ML, Fujinami RS (1994). Importance of amino acid 101 within capsid protein VP1 for modulation of Theiler's virus-induced disease. J Virol 68: 12191223.

Yong K, Khwaja A (1990). Leucocyte cellular adhesion molecules. Blood Rev 4: 211-225.

Yoshihara Y, Oka S, Ikeda J, Mori K (1991). Immunoglobulin superfamily molecules in the nervous system. Neurosci Res 10: 83-105.

Zhou L, Luo Y, Wu Y, Tsao J, Luo M (2000). Sialylation of the host receptor may modulate entry of demyelinating persistent Theiler's virus. J Virol 74: 1477-1485.

Zurbriggen A, Fujinami RS (1989). A neutralizationresistant Theiler's virus variant produces an altered disease pattern in the mouse central nervous system. J Virol 63: 1505-1513.

Zurbriggen A, Thomas C, Yamada M, Roos RP, Fujinami RS (1991). Direct evidence of a role for amino acid 101 of VP-1 in central nervous system disease in Theiler's murine encephalomyelitis virus infection. J Virol 65: 1929-1937. 